\title{
Evolution of defective structure of the irradiated silicon during natural ageing
}

\author{
I.M. Fodchuk, T.G. Gutsulyak, O.G. Himchynsky, A.V. Olijnich-Lysjuk, N.D. Raransky \\ Chernivtsy National University, 2 Kotsubynsky str., 58012 Chernivtsy, Ukraine
}

\begin{abstract}
The defective structure of silicon single crystals grown by Chochralski method $(\mathrm{Cz}-$ $\mathrm{Si})$ before and after an irradiation by high-energy electrons and gamma beams $(E \sim 18 \mathrm{MeV})$ have been studied by the X-rey acoustic resonance method (XAR) and the method of lowfrequency internal friction (LFIF). It is shown the basic types of defects that created after irradiation, have the dislocation nature. But their stability is different. It is also shown that in $\mathrm{Cz}-\mathrm{Si}$ at room temperature (more 10000 hours) the relaxation of radiation defects in the ageing process occurs on the background of disintegration of oxygen oversaturated solid solution in silicon accompanying with occurrence of essential internal tensions.
\end{abstract}

Keywords: X-ray acoustic resonance, X-ray, low-frequency internal friction, modulus shear, extinction length $\Lambda$, statistical Debay-Valler factor, relative deformation.

Paper received 10.04.02; accepted for publication 16.06.03.

\section{Introduction}

It is well-known, that characteristics of the semiconductor defective structure, its stability in time, its change under influence of various external factors will appreciably define properties both the most semiconductor material and the devices made on its basis. It is especially important for silicon which grown by Chochralski method $(\mathrm{Cz}-\mathrm{Si})$ and has a plenty of oxygen. The condition of oxygen $\left(\mathrm{O}_{i}, \mathrm{SiO}_{2}, \mathrm{SiO}_{x}\right)$ depends on temperature, concentration of other impurity and some technology factors and its essentially influences on silicon physical properties. This problem is not new, however it is investigated insufficiently especially in low temperature in the $20-400{ }^{\circ} \mathrm{C}$ range. Therefore, influence of oxygen on physical properties $\mathrm{Cz}-\mathrm{Si}$ remains a key question for development of many technological processes [1]. To the most interesting tasks of this plan which have not found the decision should refer to finding-out of laws and an investigation of oxygen low temperature precipitation mechanisms $[1,2]$ and influence on this process the intensive mechanical forces and irradiation [3].

In the present work influence of long-term natural ageing on the air and annealing in the $20-400{ }^{\circ} \mathrm{C}$ range, electronic and gamma beams irradiation on defective structure $\mathrm{Cz}$-Si has been studied.

\section{Experimental part}

Two methods of researches were chosen: a X-ray acoustic resonance method (XAR), allowing to measure with high accuracy the structural factors of real crystals and their macrodeformations level and the method of lowfrequency internal friction (LFIF) which posses high sensitivity to changes of defective structure and to structuralphase transformations in a material, especially in a complex with studying the effective shear modulus $\left(G_{e f}\right)$.

The object of research was the single crystal Cz-Si which grown in a direction $<111>$. Two series of samples were prepared for X-ray acoustic studies. Crystals of each series had approximately identical thickness. They were got from one initial single crystal. The part of samples from each series was irradiated by high-energy $(\sim 18 \mathrm{MeV})$ electrons and gamma beams and the others were used as control ones.

Experimental studies of X-rays diffraction feature of irradiated by electrons and gamma beams silicon crystals have been carried out at the excitation of acoustic 
I.M. Fodchuk et al.: Evolution of defective structure of the irradiated ...

cross-section fluctuations under conditions of the XAR. The single-crystal scheme of the diffraction (Laue-diffraction, MoK $K_{\alpha}$-radiation) was used. The distance from a source to a crystal and from a crystal to the detector was equal $\sim 0.2 \mathrm{~m}$. Thus collimation of the X-ray beam by pair cracks 50 microns wide allowed horizontal divergence of a bunch no more than 5 eng. min. For transformation of the electric fluctuations in cross-section ultrasonic converters of niobates lithium $\left(\mathrm{LiNbO}_{3}\right.$, cut $\mathrm{YZ}$ $17^{\circ}$ ) were used. Calculations of extinction length $\Lambda$, statistical Debye-Waller factor $L$ and relative deformation e were carried out according to a technique described in $[4,5]$.

Researches LFIF have been carried out on parallelepipeds $1.5 \times 1.5 \times 80 \mathrm{~mm}^{3}$ (parallelepipeds have been cut out by a long axis in a direction, perpendicular to a direction of growth) in vacuum $\sim 10^{-3} \mathrm{~Pa}$, on frequencies $\sim 2 \mathrm{~Hz}$ by the inverse torsion pendulum method. Synchronously with measurements LFIF were fixed changes of the effective shear modulus $G_{e f}$.

After machining on diamond paste ASM-1/0 samples have passed a full cycle of mechanochemical polishing for removal of the deformed layer. Studied samples were irradiated by high-energy electrons with streams $\Phi_{e}=$ $=1.8 \cdot 10^{13} \mathrm{el} / \mathrm{cm}^{2}(1 \mathrm{a})$ and $\Phi_{e}=3.6 \cdot 10^{13} \mathrm{el} / \mathrm{cm}^{2}(1 \mathrm{~b})$ and by the general doze of gamma beams $0.4 \mathrm{kGy}(2 \mathrm{a})$ and $0.8 \mathrm{kGy}(2 \mathrm{~b})$. Studies had been carried out directly after the irradiation (1a, 1b, 2a, 2b), and also after long natural ageing on time base more than 10000 hours $\left(1 \mathrm{a}^{*}\right.$, $\left.1 b *, 2 a^{*}, 2 b^{*}\right)$.

\section{Results and discussion}

XAR research studies are submitted on Fig. 1-4 and in the Table 1.

Values $\Lambda, L$ and $\varepsilon$ of control samples of the $1^{\text {st }}$ and the $2^{\text {nd }}$ groups were rather high and some different. This is

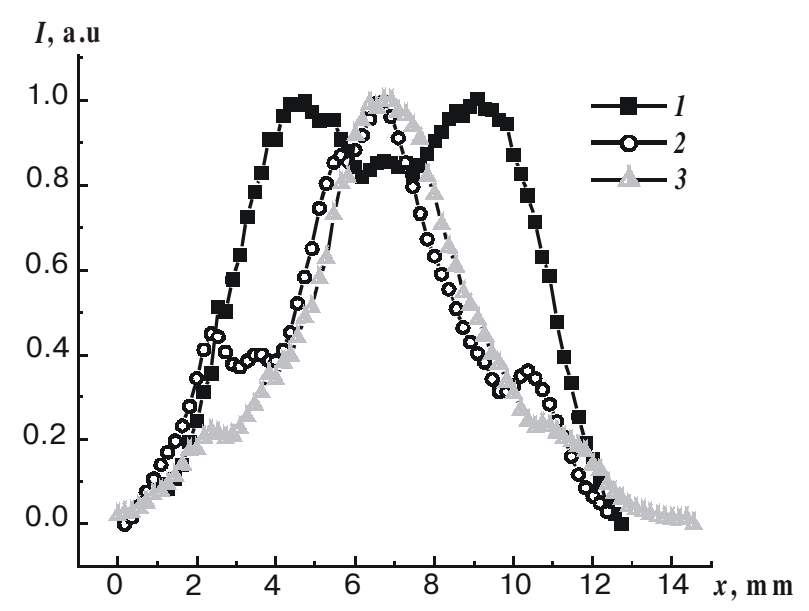

Fig. 1. Profile of spatial distribution of the relative integrated intensity $I(x)$ (symmetric (220) reflection, $\mathrm{Mo} K_{\alpha}$-radiation) for samples: 1 (1) $v=142.3 \mathrm{MHz}, U=0.48 \mathrm{~V}$; 1a (2) $v=142.3 \mathrm{MHz}$, $U=0,50 \mathrm{~V} ; 1 \mathrm{~b} \mathrm{(3)} v=142,4 \mathrm{MHz}, U=0.50 \mathrm{~V}$.
Table 1. Integral characterizations of the structure perfection of silicon single crycal definited by the XAR method.

\begin{tabular}{lllll}
\hline \hline № crystal & $\mathrm{T}, \mathrm{mm}$ & $\Lambda_{\text {exp }}, \mathrm{mkm}$ & $\mathrm{L} \cdot 10^{-2}$ & $\varepsilon \cdot 10^{-6}$ \\
\hline 1 & 4.27 & 36.62 & 0.99 & 14 \\
\hline $1 \mathrm{a}$ & 4.23 & 36.99 & 2.01 & 19 \\
\hline $1 \mathrm{~b}$ & 4.28 & 37.78 & 4.10 & 21 \\
\hline 2 & 6.48 & 36.86 & 1.65 & 19 \\
\hline $2 \mathrm{a}$ & 6.47 & 40.97 & 12.21 & 27 \\
\hline $2 \mathrm{~b}$ & 6.43 & 39.14 & 7.64 & 22.4 \\
\hline $1 *$ & 4.20 & 36.55 & 0.81 & 23 \\
\hline $1 \mathrm{a} *$ & 4.16 & 36.54 & 0.77 & 23 \\
\hline $1 \mathrm{~b} *$ & 4.21 & 36.51 & 0.69 & 24 \\
\hline $2 *$ & 0.641 & 37.06 & 2.19 & 26 \\
\hline $2 \mathrm{a} *$ & 0.6411 & 38.29 & 5.47 & 30 \\
\hline $2 \mathrm{~b}^{*}$ & 0.636 & 36.31 & 0.13 & 22.5 \\
\hline \hline
\end{tabular}

evidence of a "high" initial defectiveness and some heterogeneity of the investigated silicon crystals on volume. It is necessary to note, that the term "the high content of defects" is rather relative, as phenomenon XAR is very sensitive to total quantity of defects. So when the density of growth dislocation in the silicon crystal $>5 \cdot 10^{3} \mathrm{~cm}^{2}$ Borman effect is strongly suppressed and XAR disappears [5]. And some heterogeneity of scattering of the defects on volume as a whole is inherent in $\mathrm{Cz}-\mathrm{Si}$ [6]. In our case, selective etching of samples has shown presence of radial strips of growth. Thereof suppression of abnormal passage of X-rays by ultrasound could occur on different depth and promote some disorder of values $\Lambda, L$ and $\varepsilon$.

Natural ageing of samples of this group has led to some unexpected results: at first sight for a long time in identical conditions ageing leaded to the opposite results. So extinction length $\Lambda$ and statistical Debye-Waller factor (L) of samples of the $1^{\text {st }}$ group during ageing decreased a little bit, showing improvements of structure, and for samples of the $2^{\text {nd }}$ group they increased, showing increase of a defectiveness degree of the structure. However in both cases a relative deformation of the crystals was increasing. This testifies on passing in the ageing crystals the processes, which stimulate occurrence macrotension in samples both in the $1^{\text {st }}$, and in the $2^{\text {nd }}$ control groups. However in the first case, apparently, in silicon crystal the long period distortions of the structure prevail (with the sizes of elastic fields $l^{*}$, exceeding $\Lambda$ ), which to some extent compensate statistical average displacement of atoms under conditions of the XAR and result in effective improvement of crystal's structure ( $\Lambda$ falls) [7]. And in the second, microdefects prevail with the characteristic sizes $l^{*}($ smaller $\Lambda)$, which quantity increases during ageing $(\mathrm{L}$ increases). This results in essential deformations of the lattice. The analysis of profiles of intensity $I(x)$ to a certain extent confirms the hypotheses suggested before. Both 
the first and the second cases the character of intensity failures acoustically excited crystals testifies to the benefit of the assumption of essential increase of defectiveness during ageing. Thus, it is necessary to point out, the profiles' intensity $I(x)$ on a peripheral part has significantly increased for all aged samples in relation to the samples in an initial condition (Fig. 1 and 2) and a characteristic asymmetric shape of profiles for samples of both groups (Fig. 2 and 7, curve 1).

For finding-out of the defects' nature appearing during ageing simultaneously with researches XAR on control samples have been carried out studying temperature spectra of absorption of the elastic energy and behavior of the effective shear modulus. Results of studies have shown that during ageing at $T_{\text {room }}$ really rise of essential tensions in samples of the single crystal silicon. These tensions result to: a) sharp (almost on two order) increasing of the friction level; b) exact differentiation of absorption maxima which temperatures practically coincide with temperatures of the maxima which have been found out in spectra of the samples, deformed with a surface during mechanical polishing (Fig. 5, curves 1, 3).

It worth mention, that after mechanochemical polishing (Fig. 3, curve 2) practically all these maxima disappeared, and again appeared already during ageing. This has allowed assuming the reason of their occurrence is deformations. In the first case these are the deformations incorporated at mechanical polishing, and in the second ones appearing during ageing, and the size of the last practically is higher on the order. It is important to point out also, that ageing has led to essential change of character of behavior $G_{e f}$ with temperature (Fig. 4): curves $G_{e f}(T)$ have become two-petal. The hysteresis of curves $G_{e f}(T)$ at heating and cooling was observed in all researched temperature interval both for mechanically deformed, and for aged samples. However character of the hysteresis at those and others were different. The presence of hysteresis $G_{e}(T)$ testifies for the benefit of the

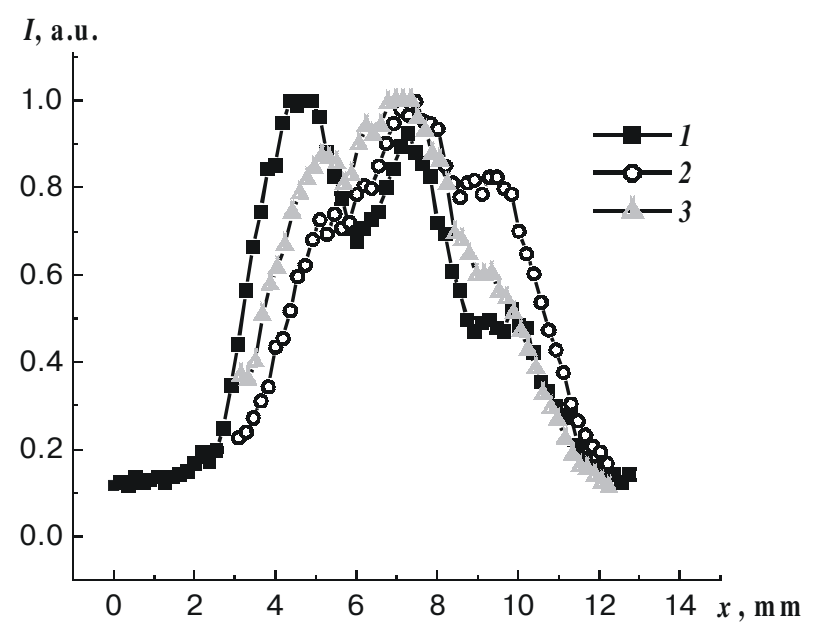

Fig. 2. Profile of spatial distribution of the relative integrated intensity $I(x)$ (symmetric (220) reflection, MoK $K_{\alpha}$-radiation) for samples: 2 (1) $v=144.5 \mathrm{MHz}, U=0.51 \mathrm{~V} ; 2 \mathrm{a}(2) v=138.8 \mathrm{MHz}$, $U=0.50 \mathrm{In} ; 2 \mathrm{~b}(3) v=139.6 \mathrm{MHz}, U=0.49 \mathrm{~V}$.

SQO, 6(2), 2003

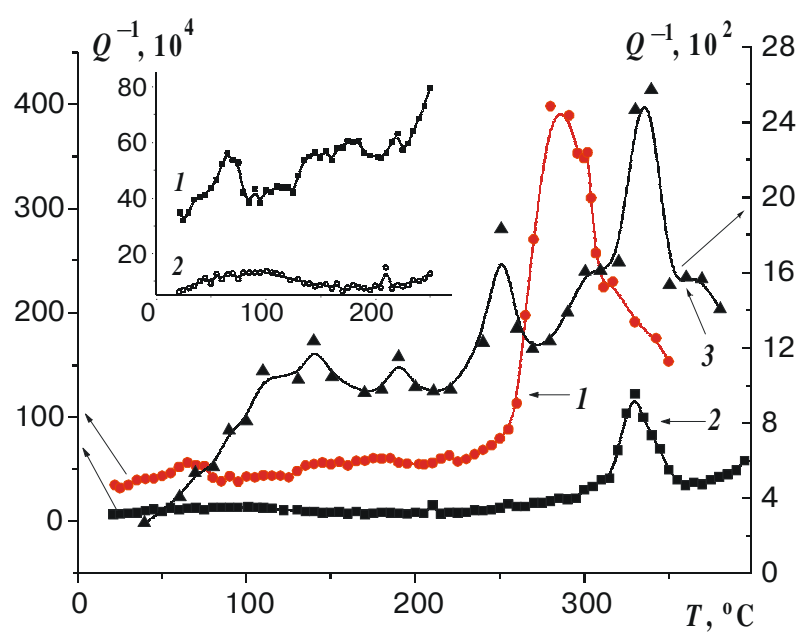

Fig. 3. Temperature dependences of the internal friction (TDIF) of control samples 1 and 2 after various processings. $I$ - after polishing on diamond paste; 2 - after chemical etching on depth up to 70 microns; 3 - after natural ageing at $\mathrm{T}_{\text {room }}$ more than $10^{4}$ hours. There are the curves 1 and 2 in the increased scale on a incut.

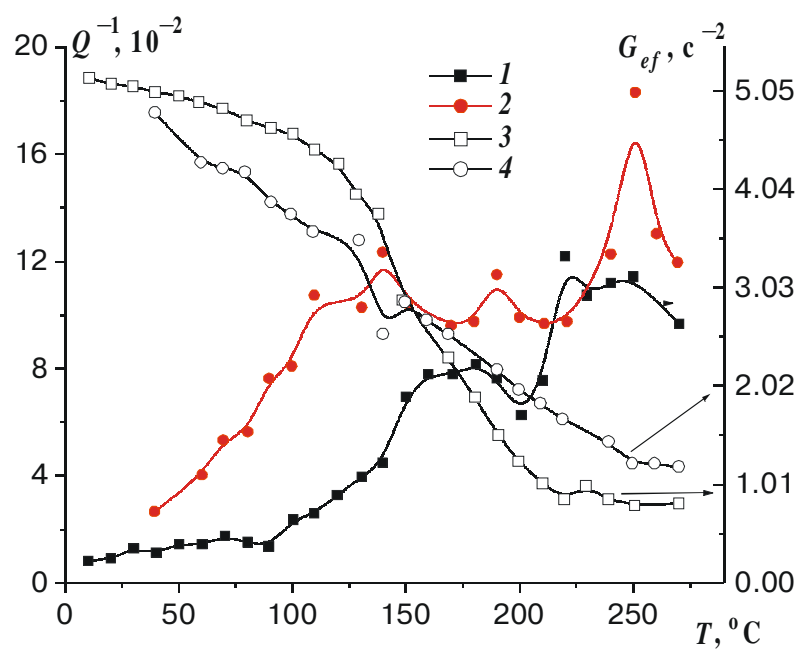

Fig. 4. $\operatorname{TDIF}(1,2)$ and $\operatorname{TD} G_{e f}(3,4)$ control samples of silicon after natural ageing for a long time and annealing at $250{ }^{\circ} \mathrm{C}(2$ hours).

estimates about the passing of phase transformations of the first type in $\mathrm{Cz}-\mathrm{Si}$ in the specified temperature interval. Apparently, in samples long ageing at $T_{\text {room }}$ could initiate disintegration process of the oversaturated solid solution of oxygen. The low temperatures, and therefore, the low diffusion mobility of the impurity atoms, have allowed us to fix the most initial stages of this process (probably formation of zones of Guinier-Preston). It is known [8], formation of these zones in a lattice is accompanied by occurrence of essential internal tensions. These tensions considerably decrease at once after transformation of coherent border between a zone and a matrix in noncoherent at the formation of an intermediate phase (and in the case of low temperatures even chains of inter- 
mediate phases) or a chemical compound. So, at the increased annealing temperatures should promote process of disintegration, allocation of detached beams intermediate phases $\mathrm{SiO}_{x}$ or phase $\mathrm{SiO}_{2}$ and to reduction of the possible tension.

For acknowledgement of this assumption, aged control samples have been undergone additional annealing at $250{ }^{\circ} \mathrm{C}$ and $400{ }^{\circ} \mathrm{C}$ different time. Annealing temperatures and time got out so that, on the one hand, to try "to finish" the processes observed in silicon in the $20-250^{\circ} \mathrm{C}$ range, and, with another hand to create, according to [1], detached precipitations of oxygen and to take off the appeared tension.

Results of studies are submitted on Figs 4 and 5. It is visible, that occurring at different times annealing at $250^{\circ} \mathrm{C}$ lead to some suppression of absorption in the 20 $100{ }^{\circ} \mathrm{C}$ range and more precise differentiation of maxima in the $100-250^{\circ} \mathrm{C}$ range. But essential changes in absorption after several hours annealing at $250{ }^{\circ} \mathrm{C}$ we did not observe. So, research results of the LFIF and $G_{e f}$ of control samples of the $2^{\text {nd }}$ group after 2 hour annealing are submitted at $250^{\circ} \mathrm{C}$ on Fig. 3. As we can see, the hysteresis of the effective module is observed in all area of temperatures. And up to $150^{\circ} \mathrm{C}$ it has normal character for phase transformations of the first type and it becomes anomalous higher this temperature. We have conditionally named such shape of two-petal curves $G_{e f}(T)$.

Annealing at $400{ }^{\circ} \mathrm{C}$ different time have led to the following: in the beginning (till 3 hours) a level of internal friction continued to increase especially in the 200 $400{ }^{\circ} \mathrm{C}$ range, but in $4-5$ hours total annealing started to decrease. Similar dependences on time of the annealing at $400{ }^{\circ} \mathrm{C}$ have got for a microhardness $(H \mu)$ of the control samples. In the beginning of this process $H \mu$ was increasing a little bit (by $8-13 \%$ ) in relation to initial microhardness, and then it was decreasing (on 18-19\%). The behaviour of level LFIF was well coordinated to the behaviour of microhardness. On Fig. 4 results of studies LFIF and $G_{e f}(T)$ for control samples annealed at $400^{\circ} \mathrm{C}$ during not less 5 hours are submitted. As we can see, such

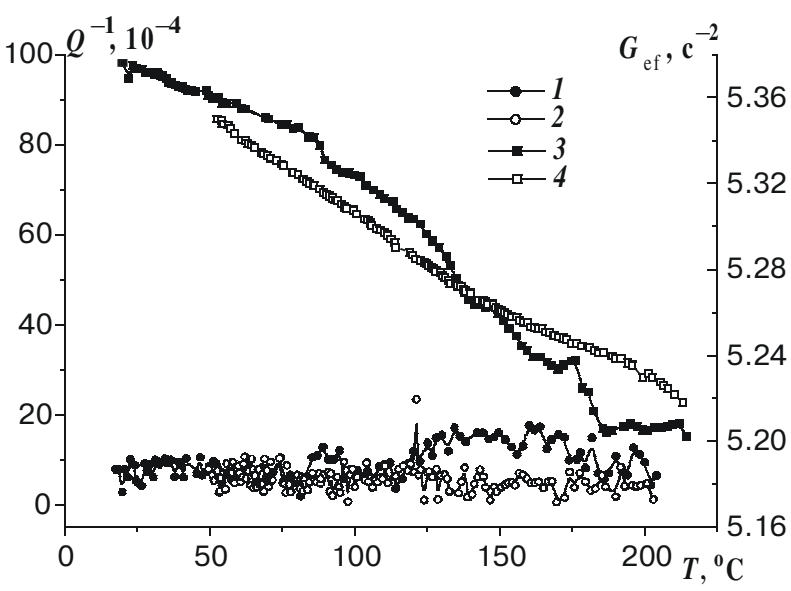

Fig. 5. $\operatorname{TDIF}(1,2)$ and $\operatorname{TD} G_{e f}(3,4)$ for the same samples after annealing at $400{ }^{\circ} \mathrm{C}$ during 5 hours. processing has led to expected results: the level of friction has decreased more than in 100 times, all maxima of absorption, except for effect in the $150-200{ }^{\circ} \mathrm{C}$ range have practically disappeared, hysteresis $G_{e f}(T)$ has considerably decreased, but two-petal character of curves $G_{e f}(T)$ has remained constant.

However closer examination of the curves $G_{e f}(T)$ after annealing at $400{ }^{\circ} \mathrm{C}$ is shown, that changes in behaviour of the effective shear modulus nevertheless have taken place. So, values of the $G_{e f}$ at $T_{\text {room }}$ before annealing at $400{ }^{\circ} \mathrm{C}$ and after it are different only on $6 \%$. And at $200{ }^{\circ} \mathrm{C}$ a difference makes about $60 \%$. In the $180-200{ }^{\circ} \mathrm{C}$ range heating curve of the $G_{e f}(T)$ after annealing were essentially nonlinear - the steps and even peaks have appeared on them - areas of an enhancement of the $G_{e f}$ with increase of a temperature have appeared; the degree of unlocking of the hysteresis loops $\left(\frac{\Delta G_{e f}\left(100^{0} C\right)}{G_{e f}\left(100^{0} C\right)}\right)$ has

sharply decreased from $18 \%$ up to $0.4 \%$.

All mentioned above gives us the basis to assert that essential internal tensions in the aged silicon samples have been fixed by methods XAR, LFIF and microhardness are result of disintegration of oxygen oversaturated solid solution in silicon at room temperatures. The analysis of a temperature spectra LIFT shows, that the level of these tensions are a high enough and considerably surpasses in the tensions increasing in silicon at mechanical polishing of a surface. Therefore, natural ageing $\mathrm{Cz}-\mathrm{Si}$ on long time bases really promotes an enhancement of the defectiveness of single crystal silicon. Probably, because of these tensions profile of the aged control samples' curve $I(x)$ have a characteristic asymmetric shape (see Fig. 2 and 7, curve 1). It is interesting to note, that, despite of some distinction of the profiles $I(x)$ for control samples of the $1^{\text {st }}$ and the $2^{\text {nd }}$ groups in an initial condition, after natural ageing they practically coincide, as if processes of ageing graded initial heterogeneity of defective structure of various silicon samples (compare curves 1 Fig. 2 and 7).

The similar cycle of researches has been lead on the irradiated samples. We shall consider influence of each kind of an irradiation separately.

Electronic irradiation. The electronic irradiation by different dozes has led to redistribution of intensity of profile $I(x)$. The essential enhancement of the intensity in the central part of a profile due to periphery is observed and it has amplified at increase in a electron doze twice. It is necessary to point out, that for samples (1a), irradiated by a doze $1.8 \cdot 10^{3} \mathrm{el} / \mathrm{cm}^{2}$, in the central and left parts of a profile appear thin structure, which is weakened (but does not disappear) in process of increasing in a doze of an irradiation (Fig. 1, curves 2 and 3). Such increase in the central part of a profile of acoustically excited crystal at a background of essential weakenning of the Borman effect is observed in work [5] where the density grown-in dislocations $N_{d}$ in single crystals of silicon has achieved $5 \cdot 10^{3} \mathrm{~cm}^{-2}$. The effect was absent, when the den- 
sity of dislocations was twice smaller. If take into account that this also took place characteristic failures of intensity $I(x)$, it is possible to assume, that in our case the irradiation of silicon by high-energy electrons leads formation of the objects of dislocations type basically. It can be big dislocation loops or klasters that create in acoustically excited crystal distortion with the size of elastic fields exceeding $\Lambda$ [7]. It should point out also, that an enhancement of a doze of the irradiation leads to a strong enough $(\sim 30 \%)$ increasing relative deformation e and in some times the Debye-Waller factor $\Lambda$. At the same time practically full suppression of all effects of absorption in spectrum LFIF is observed, at the twicegreater background of absorption and full absence of a hysteresis of the effective shear modulus. The facts mentioned prove the benefit of the assumption about the cluster nature of prevailing defects that has confirmed also selective etching.

The irradiation by gamma beams influence in a different way on the profiles of integrated intensity of the Xrays, as an irradiation by electrons. So the irradiation by a doze $0.4 \mathrm{kGy}$ also leaded to increase of the central part of a profile due to periphery and to degradation of characteristic failures of intensity, as well as at an irradiation by electrons. At the same time the increasing of gamma beams doze twice as much led to occurrence of a profile asymmetry, thin structure of the central and left maximum and increasing of the failures depth (Fig. 6, curves 2 and 3), that it is possible to treat, how result of substantial enhancement of quantity of microdefects, with the characteristic sizes $l^{*}<<$ [7].

Ageing of the samples irradiated by gamma beams occurs apparently on essentially various mechanisms in comparison with ageing samples irradiated by electrons. In fact intensity of a peripheral part of a structure increases for $30 \%$. But the curves of integrated intensity of the X-rays for samples of the 2 nd group after ageing practically coincide with curves $I(x)$ for the control samples after natural ageing (Fig. 7). Some reduction of failures

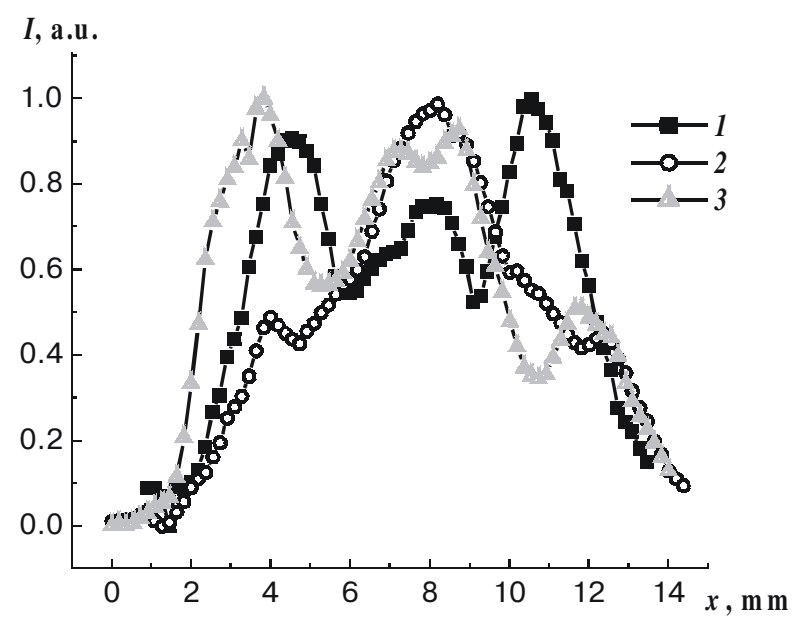

Fig. 6. Profile of spatial distribution of the relative integrated intensity $I(x)$ (symmetric (220) reflection, MoK $K_{\alpha}$-radiation) for samples: $1^{*}(1) v=149.1 \mathrm{MHz}, U=0.45 \mathrm{~V}$; $1 \mathrm{a}^{*}(2) v=148.5 \mathrm{MHz}$, $U=0.55 \mathrm{~V} ; 1 \mathrm{~b}^{*}$ (3) $v=149 \mathrm{MHz}, U=0.40 \mathrm{~V}$.

$S Q O, 6(2), 2003$

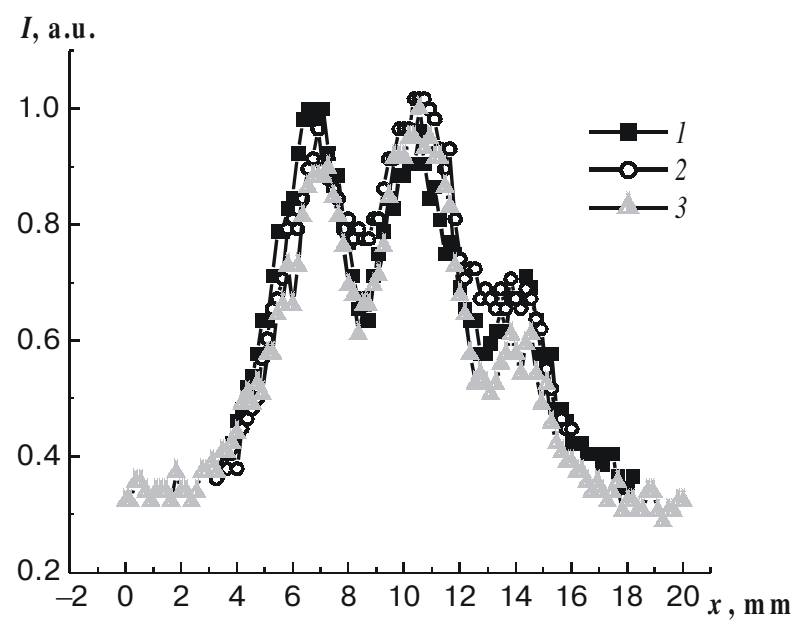

Fig. 7. Profile of spatial distribution of the relative integrated intensity $I(x)$ (symmetric (220) reflection, $\mathrm{MoK} \alpha_{\alpha}$-radiation) for samples: $2^{*}(1) v=149.7 \mathrm{MHz}, U=0.55 \mathrm{~V} ; 2 \mathrm{a}^{*}$ (2) $v=149.5 \mathrm{MHz}$, $U=0.49 \mathrm{~V} ; 2 \mathrm{~b}^{*}(3) v=149 \mathrm{MHz}, U=0.42 \mathrm{~V}$.

depth (it is especial for samples $2 \mathrm{a}^{*}$ ) and asymmetry of a structure of intensity in comparison with samples $2 *$ can testify for the benefit of prevalence in irradiated by a $0.4 \mathrm{kGy}$ doze and aged samples of defects dislocation type. As acknowledgement of received results of the spectras' LFIF and $G_{e f}(T)$ can serve. In spectra LFIF, as against the samples irradiated by electrons, background IF is restored, the effects have appeared in the $200-300{ }^{\circ} \mathrm{C}$ range, and the hysteresis of the effective shear modulus appears below $200{ }^{\circ} \mathrm{C}$. This fact can be consequence to occurrence in structure of the silicon irradiated by gamma beams the dislocation loops of the certain type. These loops can promote structural phase transformations in the specified temperatures interval.

\section{Conclusions}

1. In work the opportunity of application of the Xray acoustic resonance phenomenon for research of defective structure of the single crystal silicon grown by the Chochralski method, before and after an irradiation by high-energy electrons and gamma beams (the same both in poorly defective and strongly defective structure) is shown.

2. It is revealed, that ageing $\mathrm{Cz}-\mathrm{Si}$ at room temperatures on time base more $10^{4}$ hours has leaded to the beginning of disintegration of the oxygen oversaturated solid solution in the silicon, accompanying with occurrence of the essential internal tensions.

3. The irradiation by high-energy electrons leads to the appearance of defects basically dislocation type which action is kept and after long ageing at the room temperatures.

The irradiation by gamma beams with different dozes leads to appearance of different types of defects (diclocation and micro-) which action during ageing is practically graded by the disintegration processes of the oxygen oversaturated solid solution. 
I.M. Fodchuk et al.: Evolution of defective structure of the irradiated ...

\section{References}

1. V.M.Babich, N.I.Bletsken, E.F.Venger Oxygen in silicon crystal, Kiyv: Interpress, 1997.

2. V.V.Litvinov, G.V.Palchyk, V.I.Urenev. O vlijanii radiatsionnyh defektov na kinetiku obrazovanija termodonorov v kremnii // FTP, 24, 2, p.376 (1990).

3. V.V.Emtsev, Yu.N.Daluda, V.I.Shachovcov and others Kislorodosoderdhcaschije termodonary, obrazyjuschiicja $\mathrm{v}$ kremnii pri "horjachem" $\gamma$-obluchenii // Metallophysica, 12 , 4, p.374 (1990).

4. V.I.Kcrupa, I.P.Entin. K voprosu o vlijanii ul'trazvuka na intensivnost' rentgenovskih difraktsyonnyh refleksov // Metallophysica, 12, 4, p.80 (1990).
5. V.I.Kcrupa, O.V.Petrosan, I.P.Entin. Laue-dyfraktsija $v$ akustychno zbudhsenyh crystalah kremniju, shcho mistjat' dyslokatsii //UFJ, 36, 3, p.421 (1991).

6. R.F.Vitman, N.B.Guseyev, A.A.Lebedev and others. Vzaimosvjas' strukturno-chustvitel'nych svojstv s geneticheskimi osobennostjami monokristalovkremnija// FTT, 36, 3, p.697 (1994).

7. D.O.Grygoryev, V.I.Khrupa, L.I.Datsenko, V.F.Machulin, $\mathrm{K}$ voprosu o vlijanii kombinirovanohyh iskadhsiy structury na dinamicheskuju difraktsiju renthenovskih luchey // Metal. and Adv. Tech., 18, 6, p.47 (1996).

8. K.V.Chuistov. Nachalnije stadii raspada peresyshennija tverdyh rastvorov // Metal. and Adv. Tech., 17, 4, p.7 (1995). 